\title{
Correction to: Pregnant women with gestational diabetes and with well controlled glucose levels have decreased concentrations of individual fatty acids in maternal and cord serum
}

Henar Ortega-Senovilla ${ }^{1}$. Ute Schaefer-Graf ${ }^{2} \cdot$ Emilio Herrera $^{1}$

Published online: 1 April 2020

(C) Springer-Verlag GmbH Germany, part of Springer Nature 2020

\section{Correction to: Diabetologia}

https://doi.org/10.1007/s00125-019-05054-x

The authors regret that the incorrect figure was shown in Fig.

$3 \mathrm{~d}$. The corrected figure is reproduced here.

The online version of the original article can be found at https:/doi.org/ 10.1007/s00125-019-05054-x

Henar Ortega-Senovilla henar@ceu.es

1 Deparment of Chemistry and Biochemistry, Facultad de Farmacia, Universidad San Pablo-CEU, Ctra. Boadilla del Monte km 5,3, E-28668 Madrid, Spain

2 Deparment of Obstetrics and Gynecology, St Joseph's Hospital Center for Diabetes in Pregnancy, Berlin, Germany 
Fig. 3 Correlation between maternal and cord serum of AA and DHA concentrations in control $(n=90)(\mathrm{a}, \mathrm{c})$ and GDM $(n=84)(\mathrm{b}, \mathrm{d})$ samples. The regression line, $95 \% \mathrm{CI}$ lines and prediction limit lines are shown, together with the Pearson correlation coefficient. All values were $\log _{10}$-transformed for statistical comparisons a

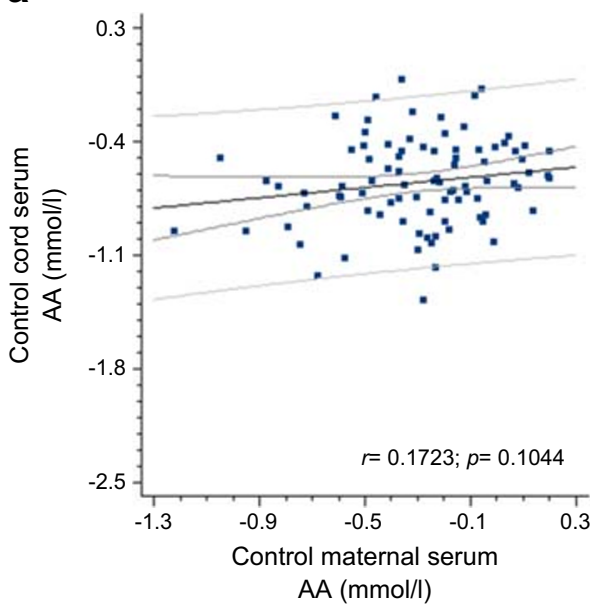

b

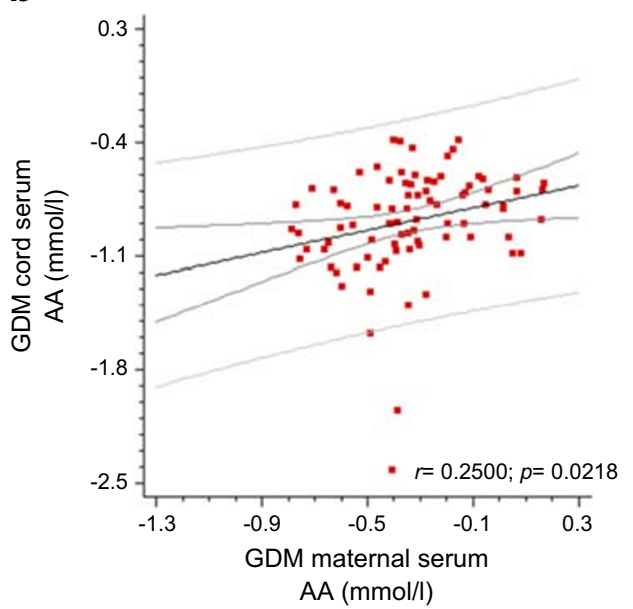

C

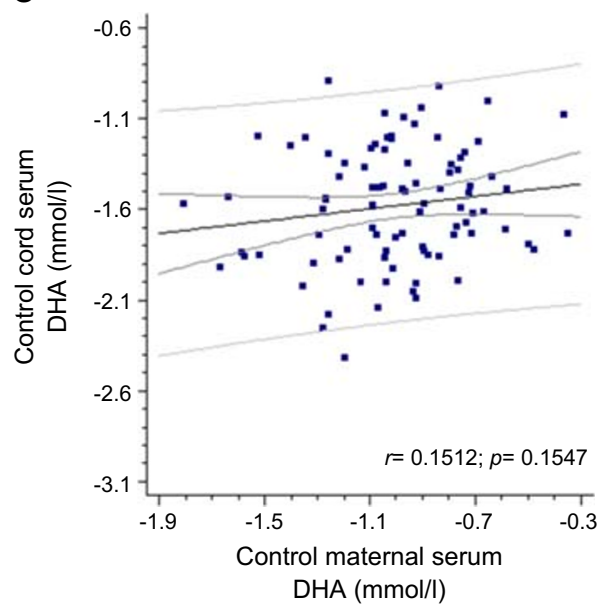

d

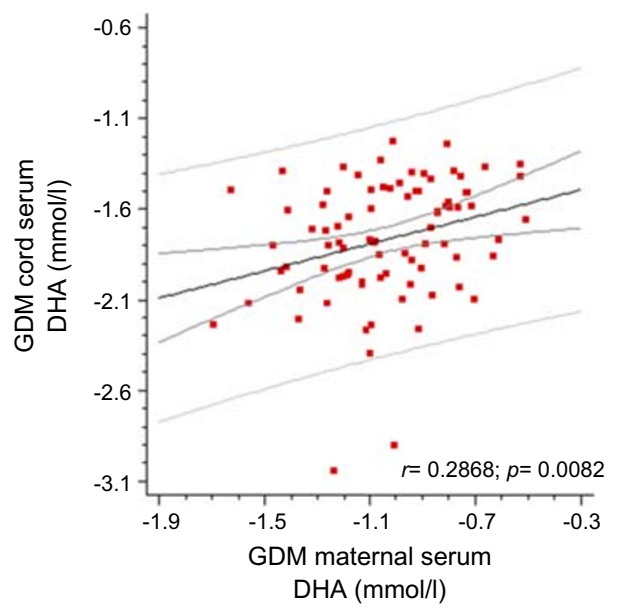

Publisher's note Springer Nature remains neutral with regard to jurisdictional claims in published maps and institutional affiliations. 